\title{
Geomechanical Estimation of the Influence of Horizontal Coalbed Methane Well Design on Coal Seam Permeability
}

\author{
Aleksandr Shevtsov ${ }^{1, *}$, and Veniamin Khyamyalyaynen ${ }^{1}$ \\ ${ }^{1}$ T.F. Gorbachev Kuzbass State Technical University, 650000, Kemerovo, Russia
}

\begin{abstract}
The paper presents a method of choosing the design of horizontal coalbed methane well by estimation of a coal seam permeability on the results of one-dimensional and two-dimensional geomechanical modeling. The differences in the preparation of one-dimensional geomechanical models of coalbed methane fields from models for conventional oil and gas fields are noted. The results of preparation of onedimensional geomechanical model based on data from one of the vertical exploration coalded methane wells and two-dimensional geomechanical modeling of coal seam for three common designs are presented. The obtained results allow us to conclude that geomechanical modeling is a suitable tool for estimation of coal seam permeability changes and choosing the most effective well design for the considered mining and geological conditions. In particular, in the coal seam under study, a multilateral well can cause the greatest increasing of permeability.
\end{abstract}

\section{Introduction}

\subsection{Relevance of the study}

The gradual depletion of oil, gas and gas condensate reserves is already forcing the industry to pay attention to those hydrocarbon sources that belong to the category of hard-torecover. Thus, the geological history of the formation of coal deposits around the world shows that the process of coalification is inextricably linked to the generation and accumulation of gas. Huge resources of gas in unrelieved coal seams and the content of methane in them more than $98 \%$ allow to consider it as an individual mineral resource suitable for commercial production [1-3].

Commercial production of coalbed methane (CBM) by wells from surface has been under way in most countries since the 1980 s, covering not only fuel requirements, but also allowing coal deposits to be prepared for subsequent safe coal mining by early degassing. As for the Russian Federation, the first CBM field was launched in Kuzbass in 2010, and in $2011 \mathrm{CBM}$ was included in the all-Russian classification of minerals and groundwater.

In world practice, CBM production is carried out mainly by vertical and directional wells, which are not characterized by high gas rates [1]. The need to increase the drainage

\footnotetext{
*Corresponding author: 1exshevtsov@yandex.ru
} 
area in order to achieve higher production rates has led the CBM industry to the widespread use of in-seam horizontal wells [2,3]. However, the resulting gas rates in the implementation of various designs of such wells vary significantly in most sources, which requires some scientific substantiation for their use in the existing mining and geological conditions.

\subsection{Purpose and objectives of the study}

In the world experience for determination of target coal seams for drilling of horizontal wells the statement that low-permeable coal seams with a thickness more than $1 \mathrm{~m}$ are candidates for horizontal drilling is used [1]. But this criterion does not take into account the fact that the stress-strain state acting in the rock massif can have a significant impact on the most important parameter of the coal seam, which provides the possibility of extracting desorbed gas - its permeability $[1,4]$. Thus, in order to provide a scientific substantiation for the use of a particular type of horizontal CBM well, it is undoubtedly necessary to develop a technique that takes into account the stresses acting in the coal seam.

The purpose of this study is to prepare and test a technique for estimation of permeability of a coal seam penetrated by a horizontal well, using geomechanical modeling methods as a common tool for the study of stress-strain state. To achieve this goal, the following tasks were performed on the example of one of the real exploration CBM wells: - determination of the stress-strain state of the coal seam in-situ by one-dimensional (1D) geomechanical modeling;

- two-dimensional (2D) modeling of the coal seam stress-strain state for various horizontal well designs;

- estimation of the permeability of the coal seam on the results of $2 \mathrm{D}$ geomechanical modeling.

\section{The study methodology and input data}

\subsection{Determination of in situ stresses}

The main components of $1 \mathrm{D}$ geomechanical models, such as pore pressure, geostatic stress, minimum horizontal stress, maximum horizontal stress and its orientation in space, are determined based on the analysis of literature and patent sources. Let us consider the proposed procedure and features of the model preparation on the basis of a standard set of tests for CBM wells.

Pore pressure for CBM fields, usually measured only in the intervals of coal seams to determine its reservoir properties as part of hydrodynamic tests. In this regard, the most suitable option is to calculate the hydrostatic pressure and determine the average percentage deviation from the reservoir pressure according to the results of hydrodynamic tests, followed by the correction of the curve.

The simplest component of the model is geostatic stress, which characterizes the weight of overlying rocks and is determined by integrating the density of these rocks, determined by the results of density logging.

On the contrary, the most difficult stage of preparation of the model - the construction of horizontal stress curves, performed using equation $(1)[1,5,6]$ :

$$
\sigma_{h}=\frac{v}{1-v}\left(\sigma_{v}-\alpha P\right)+\alpha P+\sigma_{t}
$$


where $\sigma_{h}-$ minimum horizontal stress, MPa; $v$ - Poisson ratio; $\sigma_{v}-$ geostatic (vertical) stress, MPa; $\alpha$ - Biot's constant of poroelasticity $(\sim 1) ; P$ - pore pressure, $\mathrm{MPa} ; \sigma_{t}-$ tectonic stress, MPa.

On the basis of this equation, without taking into account tectonic stresses, it is necessary to calculate the profile of the minimum horizontal stress. Then according to the available pressure values of fractures closure (according to microfracturing or injectivity tests) to calculate the tectonic stresses in the studied intervals. The resulting trend is quite suitable for adjusting the initial horizontal stress curves.

As for the maximum horizontal stress, the best option is to determine the anisotropy coefficient of horizontal stresses according to seismic studies. Also, the results of seismic studies allow to determine the direction of coal cleats. The fact that the main cleavage of coal seams extends in the direction of the maximum horizontal stress [1], allows us to obtain the final data for the construction of 1D geomechanical model - the azimuth of the maximum horizontal stress.

In Table 1 the obtained values of the parameters of a 1D geomechanical model made for the target coal seam as part of this study according to the research of one of the vertical exploration CBM wells are given.

Table 1. Parameters of 1D geomechanical model for target coal seam.

\begin{tabular}{|l|c|c|}
\hline \multicolumn{1}{|c|}{ Parameter } & $\begin{array}{c}\text { Unit of } \\
\text { measure }\end{array}$ & Value \\
\hline Pore pressure $P$ & $\mathrm{MPa}$ & 7.869 \\
\hline Geostatic stress $\sigma_{v}$ & $\mathrm{MPa}$ & 19.195 \\
\hline Minimal horizontal stress $\sigma_{h}$ & $\mathrm{MPa}$ & 9.269 \\
\hline Maximum horizontal stress $\sigma_{H}$ & $\mathrm{MPa}$ & 11.771 \\
\hline Orientation of maximum horizontal stress & degree & 317 \\
\hline
\end{tabular}

\subsection{Modeling of stress changes}

The next step is the implementation of 2D geomechanical modeling of the target coal seam with different designs of horizontal wells. For Fig. 1 the most common in the world practice variants of systems of horizontal CBM wells with vertical drainage wells $[2,7,8]$ are presented for modeling as part of this study.
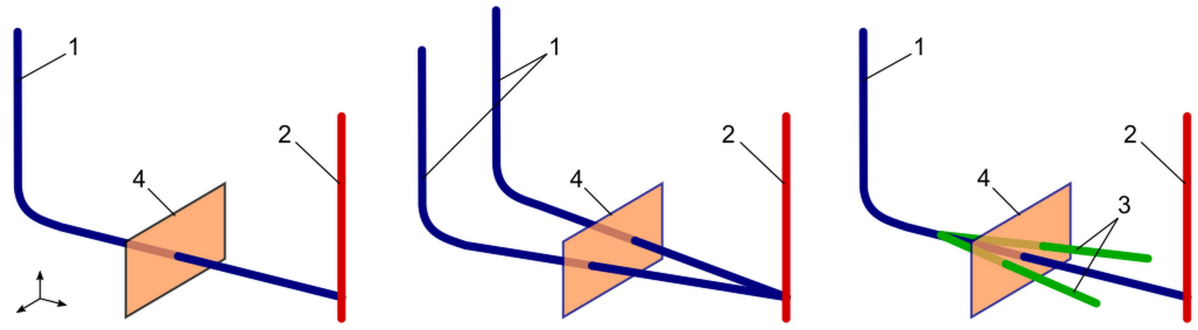

Fig. 1. The considered realization schemes of systems of horizontal CBM wells (from left to right): U-shaped, U-shaped system, multilateral well (1 - horizontal well, 2 - vertical well, 3 - laterals, 4 considered cross-section planes).

The length of the horizontal section in coal seam in all cases adopted $600 \mathrm{~m}$, main borehole is cased steel perforated liner diameter $0.1143 \mathrm{~m}$. In the case of multilateral well borehole is not cased. Also for the subsequent modeling the assumption about strictly horizontal orientation of horizontal wells is accepted, though in practice presence of some bias towards a vertical well for drainage is required. It was decided to neglect cavernosity 
of the boreholes, the angle between the boreholes of the U-shaped well system was adopted 18 degrees, between the main borehole and the laterals of the multilateral well was adopted 9 degrees.

2D geomechanical modeling is proposed to be carried out in the cross-section planes perpendicular to the horizontal axis of the considered well systems. As shown by the results of information retrieval, this approach is successfully used in the study of effective zones of influence of degassing wells on coal seams $[9,10]$.

\subsection{Estimation of permeability changes}

Equation (2) is used for estimation of coal seam permeability changing [4]:

$$
\frac{k}{k_{0}}=e^{-\alpha C_{f}\left(\sigma-\sigma_{0}\right)},
$$

where $k / k_{0}$ - ratio of the permeability of the coal seam at the current stress to the initial permeability of the coal seam; $\alpha$ - coefficient of sensitivity of the coal seam to stresses $(\sim 3)$; $C_{f}$ - coefficient of compressibility of the coal seam $\left(\sim 0,058 \mathrm{MPa}^{-1}\right) ; \sigma-$ current stress acting on the coal seam, MPa; $\sigma_{0}-$ initial stress, MPa.

Accordingly, at values $k / k_{0}=1$ there is no change in permeability, at $k / k_{0}<1$ there is a decrease in permeability, at $k / k_{0}>1$ a zone of increased permeability is formed.

\section{Results and discussion}

For Fig. 2 the obtained pattern of stress distribution in a coal seam with a single U-shaped horizontal well and the results of its permeability estimation are presented. As can be seen from the results, significant relieving zones are observed at the side walls of the well. It is noteworthy that these zones are not adjacent to the horizontal borehole and are separated from it by a small sealing zone. In this case, taking into account the flat occurrence of the seam, the results can be extended to the entire horizontal section of the well.
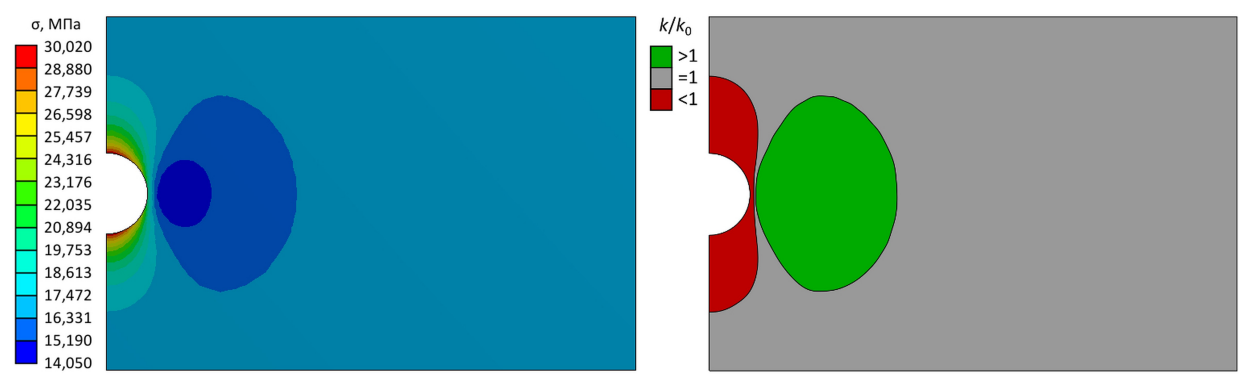

Fig. 2. Results of geomechanical modeling and estimation of coal seam permeability for U-shaped horizontal CBM well.

For 2D geomechanical modeling of a coal seam with a system of U-shaped CBM wells and multilateral CBM well were first selected cross-sectional planes in the areas of the intersection of the boreholes and, accordingly, the most significant changes of stress-strain state. Further, the calculation was made in increments of $0.5 \mathrm{~m}$ to the limit distance at which the pattern of stress-strain state distribution changes significantly.

The main results of modeling and estimation of permeability of the variant with the system of U-shaped CBM wells are presented in Fig. 3. In this case, relieving zone with a significant spreading area observed in the maximum rapprochement of the wellbore. 
Similarly a single well, this areas is separated from the walls of the wells with compression area. At a distance of $1 \mathrm{~m}$ and further from the plane of junction of the boreholes, this effect is significantly attenuated due to the formation of a large sealing zone between the boreholes.
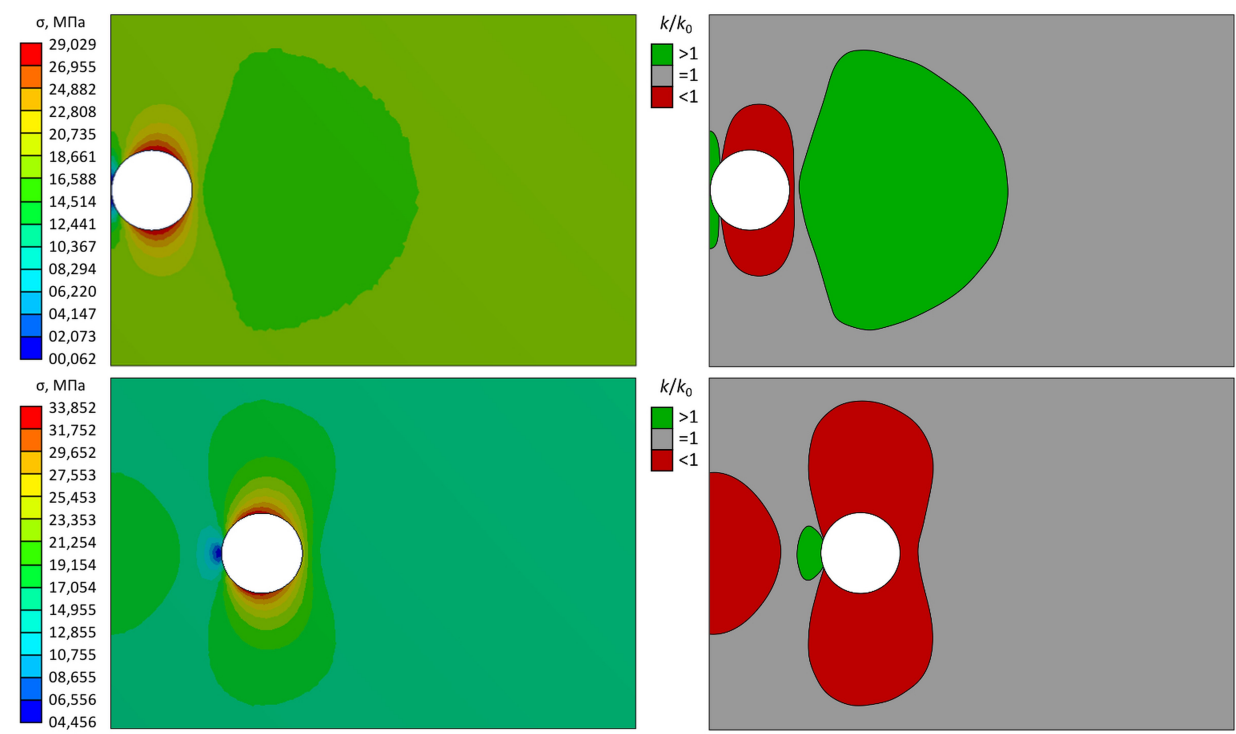

Fig. 3. Results of geomechanical modeling and estimation of coal seam permeability for two Ushaped horizontal CBM wells in the plane of boreholes junction (top) and after $1 \mathrm{~m}$ on the horizontal axis of the wells system (bottom).

Finally, Fig. 4 the main results of geomechanical modeling and estimation of permeability of a coal seam with a multilateral well are presented.
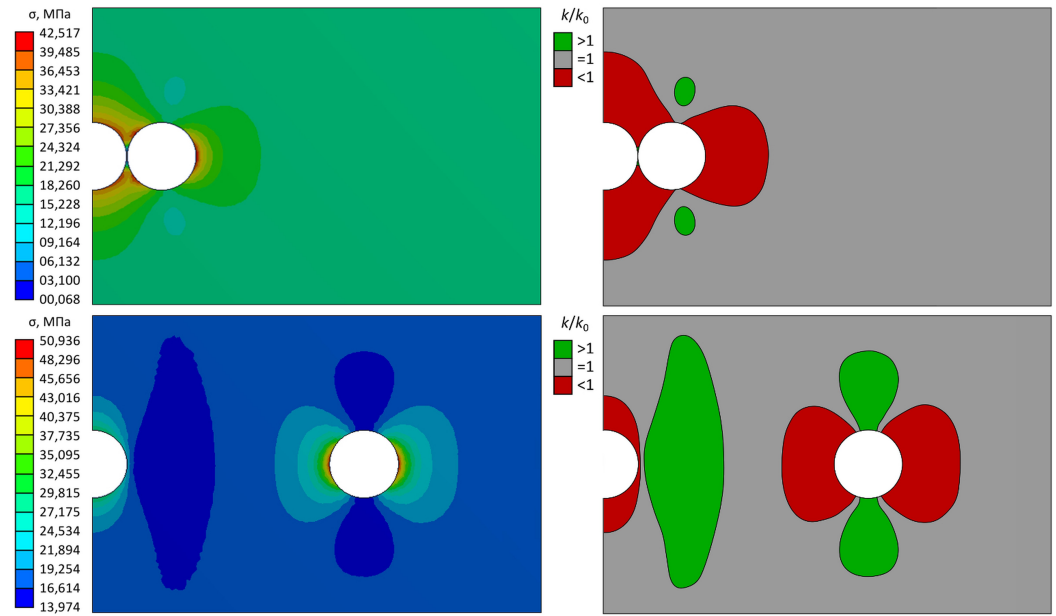

Fig. 4. Results of geomechanical modeling and estimation of coal seam permeability for multilateral CBM well in the plane of boreholes cutting-in (top) and after 2,5 $\mathrm{m}$ on the axis of the main borehole (bottom).

Despite the fact that in the plane of the articulation of the boreholes there is a fairly extensive sealing zone (due to the concentration of stresses in the places of boreholes junction), after $1 \mathrm{~m}$ there is the appearance of significant zones, relieved from stresses, 
confined to the main and additional boreholes. These relieving zones can also be observed in Fig. 4 (below), which presents the results of modeling the plane through $2.5 \mathrm{~m}$ along the axis of the main borehole from the plane of the boreholes connection.

It is noteworthy that in the case of laterals there is no compression zone adjacent to the borehole. Most likely, this is due to the absence of casing in the laterals, which in the opposite case cause rock compaction (which is confirmed by the results of modeling of the main wells in all the considered variants).

Summarizing the results of geomechanical modeling and estimation of coal seam permeability changes, it can be concluded that in the studied geological conditions the greatest increase in permeability will cause the construction of a multilateral well. It can also be assumed that the increase in the number of laterals will cause additional relieving of the rock massif from stresses and increase the permeability of the target coal seam.

\section{Conclusions}

The results of the study show that geomechanical modeling is a suitable tool for estimation of change in the permeability of the coal seam and choosing the most effective for the considered geological conditions of the design of a horizontal CBM well. For example, in the coal seam under study as part of this work, the greatest increase in permeability can be caused by the construction of a multilateral well. The obtained result is due to the absence of casing in the laterals, which contributes to the coal seam decompression in these areas. In the future, it is possible to continue research in the part of geomechanical modeling of a real horizontal CBM well with subsequent comparison of the results with the parameters of its production.

\section{References}

1. R. E. Rogers, K. Ramurthy, G. Rodvelt, M. Mullen, Coal Bed Methane: Principles and Practices (Oktibbeha Publishing Co., Starkville, 2007)

2. P. Thakur, S. Schatzel, K. Aminian, Coal Bed Methane: From Prospect to Pipeline (Elsevier Inc., San Diego, 2014)

3. P. Thakur, Advanced reservoir and production engineering for coal bed methane. $1^{\text {st }}$ ed. (Elsevier Inc., Morgantown, 2017)

4. J. Seidle, Fundamentals of Coalbed Methane Reservoir Engineering, (PennWell Corporation, Tulsa, 2011)

5. M.D. Zoback, Reservoir Geomechanics (Cambridge University Press, Cambridge, 2010)

6. M. T. Hayavi, M. Abdideh, Rus. J. of Earth Sc., 16 (2016)

7. Y. Yang, S. Cui, Y. Ni, F. Wang, Y. Yang, and etc, Nat. Gas Ind. B, 2 (2014)

8. Y. Zhang, Y. Yang, G. Shao, L. Chen, N. Wei, and etc, Nat. Gas Ind. B, 4 (2017)

9. J. Xie, M. Gao, B. Yu, R. Zhang, W. Jin, Geomech. Geophys. Geo-energ. Geo-resour., 1:2 (2015)

10. H. Zhang, Y. Cheng, Q. Liu, L. Yuan, J. Dong, and etc, J. of Nat. Gas Sc. and Engineer., 46 (2017) 